\title{
ASPECTS ON E-LEARNING DURING THE COVID19 PANDEMIC AT THE UNIVERSITY
}

\author{
Vlad Drăgoi ${ }^{1}$ and Dorin Herlo ${ }^{1}$ \\ "Aurel Vlaicu" University of Arad, Romania \\ ${ }^{1} \mathrm{PhD}$
}

\begin{abstract}
The rapid developments in educational technologies and the conditions of pandemic period provoked the academic staff and students for assessing the value of different technologies, new or existing, and for deciding how or when these technologies make sense for them to use. Due to crisis, face-to-face learning process was change with Emergency Remote Teaching. In this article we approached the case study for university education, on the use of learning platforms, to increase reflective learning, critical reflection and concrete action of students in real life which are clear elements of transformative learning and related to the new educational paradigm - paragogy (peer-learning). In order to have a significant outcome of our proposed solutions, we proceed in two-steps. Firstly, we detail and test some of the existing e-learning tools (platforms), and secondly, based on a focus-group experience with groups of students enrolled in computer-science Bachelor degree, we propose adapted solutions for online learning and teaching for the next academic year.
\end{abstract}

\section{KEYWORDS}

E-Learning, Transformative Learning, Paragogy, Case Study, Focus Group

\section{INTRODUCTION}

Being involved, like everyone else in this world in the pandemic days, in the need to take online university courses, we proceeded, with students from exact sciences, to shift to the Emergency Remote Teaching (ERT) that involves the use of fully remote teaching instead of courses delivered face-to-face or as blended. Under the given conditions we set out to offer students the same curriculum but exploring various tools like platforms.

However, we kept the idea of producing transformative and not transmissive learning that appeals very well to e-learning. Transformative learning (Mezirow, 1991) involved critical reflection, reflective discourse and action. In our case, critical reflection is converted in thinking about what tools, offered by virtual learning environment, could be used easier and more effective for accomplishing the objectives of learning. Reflective discourse and action, consist in using the e-learning tools, chosen in critical reflection phase, for a good and efficient learning.

In our study we addressed these three essential parts of transformative learning related to e-learning, especially, in this particular case, with ERT studying with the students the behavior of three platforms - Skype, Zoom and Discord.

At the same time, we think that our case study also highlighted few elements of new educational paradigm - paragogy. The concept of paragogy (literally, "para-" alongside, "-gogy" leading) it's used to characterize the critical study and practice of peer learning.

In the idea of supporting our approach, we conducted practical case study with students enrolled at a public University in Romania, having a rather scientific background and orientation. As we were aiming for qualitative responses to new and challenging questions, we used focus-groups interviews on which an online course proposal oriented to individual with low resources was developed. 


\section{METHODS}

\subsection{E-learning}

E-learning - learning system helped by electronic resources - is known as a network enabled transfer of knowledge and skills, to a large number of recipients (educables) at the same or different times, using different kind of IT tools, aiming for "delivering" education.

As an educational paradigm "E-learning is defined as information and communication technologies used to support students to improve their learning" (Ellis et al., 2009).

A Delphi survey was used to determine experts' perceptions and knowledge, that might converge to a final consensus of an inclusive definition for e-learning. This method (Delphi) makes possible to deal with complex problems (Linstone \& Turoff, 1975). Recently, 33 experts from over the world were asked to evaluate e-learning definition, in the final Delphi round. Their conclusion was: "E-learning is an approach to teaching and learning, representing all or part of the educational model applied, that is based on the use of electronic media and devices as tools for improving access to training, communication and interaction and that facilitates the adoption of new ways of understanding and developing learning."

We can say that in their definition the experts mainly characterized e-learning as a "way of teaching and learning" moving towards a "new educational paradigm" and, from our perspective, the new educational paradigm is the paragogy.

The term paragogy, as per its founders Corneli and Danoff (2011), it is employed to characterize the critical study and practice of peer learning (here adapting the classical concept of pedagogy and the notion of andragogy to a peer learning context). In essence, Corneli and Danoff's paragogy thesis is premised on the argument that online environments are now sufficiently developed to support peer production of content which can be shared freely and widely, and can promote learning for all within any given community. So, paragogy deals with a very important challenge, i.e., of analyzing and co-creating the educational environment as a whole by the peers, which share their learning situations and experiences, benefiting of information technology, used for connecting people. This means creating "wisdom" starting from "data", "information" and "knowledge".

In special conditions of pandemic period a sort of e-learning that we used was Emergency Remote Teaching. "ERT is a temporary shift of instructional delivery to an alternate delivery mode due to crisis circumstances. It involves the use of fully remote teaching solutions for instruction or education that would otherwise be delivered face-to-face or as blended or hybrid courses and that will return to that format once the crisis or emergency has abated.” (Hodges \& all, 2020).

\subsection{Case Study}

A case study is a research method involving an up-close, in-depth, and detailed examination of a particular case and can involve both qualitative and quantitative research methods. A case study implies the observance of the following steps: case identification; objective documentation on cases and identification of intervention modalities; applying the modalities of intervention on the case, of solving it; monitoring the evolution of the case. Our case study is qualitative and exploratory, mainly because its basic function is to help identify questions and select types of measurement prior to the main investigation.

\subsection{Focus Groups}

The technique of regrouping a set of individuals in order to discuss on a specific topic, aiming to analyze and built constructive qualitative decisions based on the personal experiences, perceptions and attitudes of the participants, is known as focus group discussions (Cornwall \& Jewkes 1995, Hayward et al., 2004, Morgan 1996). The method was already applied in education (Flores \& Alonso, 1995). The four major steps in a focus group are:

- Research design. Here we define the objectives by fixing the main purpose of the focus group, develop a set of possible questions, recruit the participants (ensure homogeneity, max 15 participants per group, number of groups), identify the possible locations. 
- Data collection. This step is mainly focused on the preparations, recording, tapping the content, and implementing the sessions by following four major principles, namely Introduction, Discussions, Questions, and Conclusions.

- Analysis. Here we analyze the content of the meetings by various methods, e.g., Coding, Discourse analysis, Ranking, Conversation analysis.

- Results. Depending on the target audience different reporting methods are used. In our case we address our study to the academic audience and hence conclude our report in a constructive manner, by proposing an e-learning method combined with classical tools, part of which we tested at our university.

\section{RESULTS}

We started the case study at the beginning of March 2020.

In the first step we identified the case - how the academic curriculum can be delivered as efficiently as possible through e-learning platforms for producing transformative and not transmissive learning for the students.

In the second step - objective documentation and identification of intervention modalities - we requested the students to search the information concerning the Skype, Zoom and Discord platforms. For this action they had to install the application in order to test it and compare it with other similar applications. In this step we used, for communication, the classical tools such as the email, social networks and phones. For academic staff it was a very short period of adapting the course or seminar to the needs of the student for accessed them online (either synchronously or asynchronously) to produce critical reflection, then a reflective speech (after understanding) and, finally, application in practice of notions understood by action. In other words, to produce transformative learning. In the first two weeks we tested three different platforms for video conference (see Table 1).

Table 1. Video conference platforms (free version)

\begin{tabular}{|c|c|c|c|}
\hline & Skype & Zoom & Discord \\
\hline Popularity (students) & $\begin{array}{l}\text { Very popular, } 100 \% \text { of the } \\
\text { students already knew the } \\
\text { platform before we started. }\end{array}$ & $\begin{array}{l}\text { Popular, } 80 \% \text { of the } \\
\text { students heard/knew the } \\
\text { platform before our study. }\end{array}$ & $\begin{array}{l}\text { Almost unknown, } 5 \% \text { of } \\
\text { the students used this } \\
\text { platform in the past. }\end{array}$ \\
\hline Participants & $\begin{array}{l}\text { Max } 50 \text {. At } 35 \text { users we } \\
\text { experienced video and } \\
\text { voice problems during the } \\
\text { sessions. }\end{array}$ & $\begin{array}{l}\text { Max. 100. More reliable } \\
\text { than Skype regarding the } \\
\text { voice and video quality at } \\
\text { high number of } \\
\text { participants. }\end{array}$ & $\begin{array}{l}\text { Max } 99 . \text { We only tested a } \\
\text { group of } 8 \text {, and the voice } \\
\text { and video quality were } \\
\text { exceptional. }\end{array}$ \\
\hline Video recordings & Available for 30 days & Until $1 \mathrm{~GB}$ on the cloud & $\begin{array}{l}\text { Unlimited (as mentioned } \\
\text { by the developers) }\end{array}$ \\
\hline Quality & $\begin{array}{l}\text { Video and voice quality } \\
\text { were acceptable for small } \\
\text { groups. When two or more } \\
\text { participants speak/turn on } \\
\text { their camera the quality } \\
\text { drops down. }\end{array}$ & $\begin{array}{l}\text { The quality is very good } \\
\text { for small groups and } \\
\text { acceptable for large ones. } \\
\text { Even when several } \\
\text { cameras are turned on the } \\
\text { image remains clear. }\end{array}$ & $\begin{array}{l}\text { Excellent for small groups, } \\
\text { both the image and sound } \\
\text { quality are very good even } \\
\text { when several users are } \\
\text { activating these options. }\end{array}$ \\
\hline Security & $\begin{array}{l}\text { Skype - Skype chats, both } \\
\text { video and audio are } \\
\text { encrypted. }\end{array}$ & $\begin{array}{l}\text { Zoom } 5.0 \text { introduced an } \\
\text { option for secure } \\
\text { communications. }\end{array}$ & $\begin{array}{l}\text { There are some doubts } \\
\text { regarding its security. }\end{array}$ \\
\hline Screen sharing & Yes & Yes & Yes \\
\hline CPU & $\begin{array}{l}\text { Extremely high use of } \\
\text { CPU. }\end{array}$ & High & Low \\
\hline Time limits & $\begin{array}{l}\text { In the platforms } \\
\text { specifications there is no } \\
\text { time limit. }\end{array}$ & $\begin{array}{l}40 \text { minutes for basic } \\
\text { members. }\end{array}$ & No time limits mentioned. \\
\hline User-friendly & $\begin{array}{l}\text { Easy to use but ambiguous } \\
\text { in identifying users or } \\
\text { Skype ids. }\end{array}$ & $\begin{array}{l}\text { Easy to use and the } \\
\text { connection is very easy } \\
\text { once the conference rooms } \\
\text { is set up. }\end{array}$ & $\begin{array}{l}\text { Easy to use once we were } \\
\text { invited on a server. }\end{array}$ \\
\hline
\end{tabular}


We rapidly realized that we could propose a solid way based on completely free, online available platforms. Setting up such an environment, with no technical discrimination between the students, was necessary to release the pressure students started to experience at the beginning of the isolation. In this manner we created similar, non-discriminate, and uniform infrastructure for all the participants.

Finally, we have decided to continue with Zoom. One of the leading arguments for this choice was the possibility of having, in the free version, simultaneous webcams switched on. As simple as it might look, this option kept our connection and relations closer to the face-to-face scenario. This is a real advantage when we are dealing with long periods of isolation.

In the third step - applying the modalities of intervention on the case, of solving it - the academic staff provided the official curriculum for the student's specialization via Zoom, using ERT. For this action it was necessary a schedule/timetable. By the way, planning projects and group meetings is a basic feature one needs to take into consideration when working online. The application chosen by us for such activities was Doodle (www.doodle.com). The application does not require any installation or sign-in process by the participants. The administrator/creator or the pool designs the online voting procedure by creating multiple choices possibilities. After each participant has voted a majority voting gives the output, which can be exported in several different formats, among which the most common one is pdf files.

When the delivery of the online course started, from the faculty point of view, student learning outcomes were of primary interest. For this reason they proposed various learning activities supported by interactive methods such as brainstorming, online editing, problem solving, inquiring, algorithmization, collaborative learning, projects etc. supported by well-known platforms such as Overleaf (www.overleaf.com). Overleaf allows users to edit, modify, save LaTeX documents on the Cloud. The main advantage of using such a platform is that one can use all the resources, namely the editor, the compiler, the templates, without having to locally store any software/documents/libraries. The platform proposes a chat and comments frame alongside the text and pdf document, fact that allow users to discuss directly on the platform regarding the modifications to be made on the document. Also, the large list of templates proposed by IEEE, Springer, ACM and others, are available directly on the platform. Among the most popular tags proposed by Overleaf we recall here, presentations, project/lab report, thesis, formal letters, $\mathrm{CV}$, posters, etc.

For students, issues such as interest, motivation, and engagement are directly connected to learning satisfaction and success of applying all the concepts/ notions in the real life (environment).

In the fourth step - monitoring the evolution of the case - we proceeded to do a focus group.

Let us detail the main steps of our focus group.

Research Design. The purpose of our focus group was to determine "good"/ "bad" practice on e-learning implementations, due to the Covid 19 global pandemic. We have implemented our research on homogeneous mixed gender groups of students. They are all enrolled in Bachelor degree scientific studies, in mathematics and computer science, at different levels. We organized three groups, i.e., a first group of 15 first year students in computer science, a second group of 7 second year students in mathematics, and a third group of 2 third year students in computer science. All three groups present the following characteristics. They are uniformly distributed between rural and urban provenience, the students do not have any part time jobs except for 2 out of the 15 students of the first group. Also, they all share a modest financial situation, and finally, their scholar performance being close to the average (here we considered the discrete probability distribution of the grades for each year separately). Our choice is based on some well-known principles, such as group dynamics (Green \& Dowler 2003, Thomas et al., 1995), homogenous principles (Krueger, 1994), and mixed gender groups (Freitas et al., 1998). The number of participants follow typical focus groups guidelines, suggested in (Krueger \& Casey, 2000, Fern, 1982, Mendes de Almeida, 1980). We organized two focus groups with the first group of students, and one focus group with the two others. These were organized on an online platform, in our case the Zoom platform, and are known as online focus groups in the literature (Kamberelis \& Dimitriadis, 2005).

Let us present a selection of the questions asked during the focus groups.

- Did you talked with your classmates or teachers about the technology used for teaching?

- Did you had any discussion with your friends about how you felt during the look down?

- How the selection of the technologies was made? Were you consulted in this process?

- On a scale of 1 to 7 at what level was the online teaching, in average? Which are the extreme cases?

- Let us suppose that next academic year does not start in the classic manner. What do you propose as viable solution? 
- What exactly do you think the online teaching/learning revealed about yourself? In what way did it help you?

Data collection. We have decided to collect our data by recording the sessions, fact that was mainly imposed by the context of that time. In order to keep the meetings as active and dynamic as possible we have maintained a 2-hour limit. Surprisingly or not, the smallest group was the most dynamic one, and the discussions inside this group were extremely interesting pointing out several roads of future developments and applications of the e-learning methods. One of the key advantages of using a web-based platform is that younger generations manipulate and feel natural in using such tool. Also known as the connected generation, our students felt extremely relaxed and comfortable during the sessions, and as stressed out by several participants this is due to the online wall between them. The main drawbacks of our collecting the data is that it was almost impossible for us to collect non-verbal data, such as body language, displacement or posture and their use of the physical space to communicate. However, some informal data such as speech markers (volume variations, pitch, gaps) were included in our analysis.

Analysis. We have analyzed our recordings and proceed to an encoding of the data transcripts from the meetings. We have classified the data into three major folders, i.e., "Illustrative quotations", "Positive points", "Less positive points", fact that allowed us to discover several patterns.

\section{Results.}

Illustrative quotations. During our study we have noticed key elements of the psychological impact, such as weakening attention during learning activities, long moments of fatigue, and feelings of loneliness. Some of the students felt sad and alone, mainly due to the lack of human contact. The students confessed that they felt the need to socialize, to physically interact with each other, and also with their teachers, fact illustrated by the following quotation made by one student: After several weeks of lock down and online teaching, we finally understood what "students live" really means. I miss the long coffee breaks, the time our colleagues are late for the computer graphics course and being punished by our teacher, the long nights spent with our project colleagues while trying to finish the report and the final implementation, and the time we all look at each other when the algebra teacher was asking questions. We lost all those simple and beautiful things during the pandemics.

Since the isolation naturally induces such feelings, the online teaching and learning should clearly not enforce such pessimistic moods.

Positive points: The e-learning process could potentially come into help by steering the students mind to new fields, and also by providing satisfaction, pleasure and curiosity regarding the learning process. Interactive methods and using the adequate tools induce a desire/curiosity for how the application works, how groups of students can use it in order to build a project, organize their ideas and finally to learn. The fact that many of the modules tend to closely imitate the physical objects, like boards, stamps, pens, etc., gives us the impression of handling real physical objects through our computer. However, the overall idea pointed out by the students was that e-learning might provide an effective and healthy environment but for short term activities and it should not completely replace the face-to-face teaching. As long as the both the students and the teachers are equipped with adequate technology the learning/teaching process does not induce any particular initial differences. Another point revealed during the sessions was that all the effort done by the teachers to make students learn, use, combine, and adapt technology for learning and teaching was highly appreciated by the students. Students' confession: A math teacher has had preoccupation to demonstrate us, on a digital tablet equipped with white-board emulator, how could be explain and prove theorems for algebra, in an interactive and pleasant way. We felt like we were in the classroom and our teacher was in front of us. The students confessed that they realized that interactive learning means effective participation on both side: teacher-student and academic staff used teaching-learning-assessment methods very well, suited to the online environment.

The focus-groups revealed positive qualities and abilities developed by the students, that are strangely related to the effect of the online teaching/learning. Several students confessed that they became much more organized, fact that they believe it was induced by the online process. They had to keep a complex updated agenda with their courses, project, meetings etc. Also, they are willing to help their colleagues in a more accentuated and frequent manner, which was not always the case before the lock down.

Less positive points: A first idea detached is that more than three months of physical isolation could potentially induced irreversible psychological damage to the individuals. Even though psychological impacts or measures for dealing with this new type of human relations were previously identified and published (Taylor, 2019), these methods were not sufficiently explained or taught in high-schools or universities. Another point deduced from focus groups was that many students, for various reasons, were not able to provide themselves 
with the necessary materials, e.g., cameras for the laptops, software for editing, programming etc. This fact induces a polarization among the students, which would clearly affect their performance and utterly change the dynamics of the groups. Eventually, the lack of a technological infrastructure could induce psychological disorder. That is why, we chosen to eliminate as much as possible discriminatory variables, and proposed to students as few software/applications as possible in order to complete the course. Respondents from focus groups pointed out another critical fact - the physical location that students used for their online courses. $32 \%$ of the students mentioned physical infrastructure problems cause by different factors, such as, neighbors, roommates, family, outdoor activities, etc. For half of them the main reasons were the living conditions, namely, they were living with their parents, grand-parents, in small flats. Another relevant aspect, provided by the few quantitative data collected (e.g., level of online teaching per course) revealed a phenomenon of polarization. More exactly, we computed the distribution of levels (on a scale of 1 to 7) of online teaching for each course. We noticed an average grade equal to 3,8. However, the distribution of the grades was not at all Gaussian (as expected). The majority of the courses were either "good" (6) and "very good" (7) or "bad" (2) and "very bad" (1).

\section{DISCUSSIONS}

When the Universities were closed and the teaching went from face-to-face to online, both students and professors had to adapt their behavior for teaching and learning. For academic staff was a great challenge to shift their courses from face-to-face into online, appealing for a way that in the literature is called Emergency Remote Teaching. As we were confronted with a new paradigm in terms of behavior, education, health the communication process was not always convincing and stable, e.g., the content of the program was updated during the teaching process, and the evaluation methods were changed during the semester from work tasks, from one meeting to another, up to short project presentations and the creation of e-portfolios, evaluable at the end of the semester.

Students seem to easily adapt to digital technologies, Internet based platforms for communication, or any other computer-based technology (Dede, 2005, Howe \& Strauss, 2000, Oblinger \& Oblinger, 2005, Prensky, 2001, Tapscott, 2008), what we found, as well. They appreciated and felt involved in the whole process when planning and collaboration where decided together with the teacher. For that, they stressed out the importance of platforms such as Doodle and Zoom. Their contribution was valued, e.g., they proposed the Zoom platform for video conference, application that we tested together. They were also pro-active in the teaching/learning process and substantially contributed to the design of online lecture architecture.

We can give, here, a detailed example of an online learning activity, combined with discussions and project proposal that was implemented at our university. We worked with a group of seven students in their third year of Bachelor degree in computer science. The subject we proposed was to study the security of a post-quantum cryptosystem. All combined, we had three presentations on this subject, and after the students prepared a project. Technologies such as YouTube video, Zoom, Doodle, Miro and WhatsApp were used in order to achieve our goal. Also, we had a Windows 10 Pro for Desktop Stations equipped with the Microsoft Whiteboard application.

The first course was a presentation of the fundamental notions that we were about to study. We used the Zoom platform and the Microsoft Whiteboard in order to detail, and comment on these initial requirements. While this first course looked very likely to classic lectures, the two following sessions were completely different from a classical computer science lecture. More exactly, during this first course we set up the strategy for learning and getting really into the subject of cryptography. The main goal was to make the students discover by their own the subject (discovery learning), and force them to take some deep thinking (critical reflection) on the issues raised by the topic. Based on the idea that the information gets saved and remembered more efficiently if several physical senses are used, we propose them audio descriptions/definitions, video recordings on the topic, as well as written notes to be taken. In this way the students used their sight, touch, and hearing in order to record the information. The videos are free online MOOC tutorials.

In this way, we challenged the students to build their own reflective discourse based on their previous reflections to then, implement it. 
The second and the third courses were interactive, using the questionnaire with open-end answers, e.g., how does a public key encryption scheme work, what is the security of a cryptosystem, what issues are to deal with when implementing such a solution, etc. We were discussing on Zoom and adding content to a spreadsheet on Miro. The technique was extremely appreciated by the students, for several reasons.

- First of all, the classical learning methods using transmissive techniques and repetitions was changed into a process of discovery, research, reflecting and using in a positive way the knowledge. This procedure revealed students that they are able to find the information, select, understand, analyze, synthetize, evaluate and create their own knowledge (following somewhat modified Bloom's taxonomy), guided by the academic staff.

- Discussing all together, students and professor, in a collaborative style, tends to strengthen the relation between the two sides. The learning process becomes in this way a vector for a more human and social relation involving the respect and responsibility of the parties for a job well done.

- Another constructive aspect was that it shapes student's characters with rigor, respect, a high sense of responsibility and collaboration. They had to sustain their ideas in from of the others and by doing so they were confronted with questions and doubts. In order to successfully achieve their goals, they developed their skills, abilities and attitudes with elements of transformative learning and even of peer learning (paragogy).

The last step was a project proposal were the students came with the idea of implementing one solution the general cryptographic problem. We organized private groups on WhatsApp, planned meeting with Doodle, and used overleaf to collaborate on the project development.

\section{CONCLUSION}

Starting from a reality - the pandemic - in this article we tried to capture, through a case study, aspects of online learning carried out in the university, with students from exact sciences specialization.

Academic staff was forced to adapt their courses very quickly to deliver them online using the so-called Emergency Remote Teaching, which involves the use of fully remote teaching solutions for instruction or education that would otherwise be delivered face-to-face or as blended courses.

The whole process started with the study of several free IT solutions for online collaboration, video conferencing, online editing, scheduling or even project management, such as, Zoom, Overleaf, Miro, Doodle.

The way to move from transmissive to transformative learning was also pursued by the teaching staff, in condition to use effectively IT tools. By means of different devices the students were connected peer-to-peer and with academic staff for emphasized the idea of visible learning (Hattie, 2011). More precisely, the teaching and learning methods used (interactive) provide a well-being experience, induced by curiosity and the online collaboration. At the same time, through critical reflection, reflective discourse, action caused by professors and produced by students the foundations were laid for transformative learning. This way leads us to a learning model between uniform and equal individuals, under an academic supervision.

This particular state-of-mind helped students to overcome feelings induced by the isolation, such as loneliness, sadness.

In our examples of good practices, we highlighted that the teaching/learning/evaluation methods we proposed, helped by IT solutions, enabled the student to self-discover the nature of the objects, their relation with the real life, and the true relation with its colleagues, and finally, itself.

One might find some disadvantages in our case study, e.g., the size of the groups is limited to 15 students or the fact that teachers are not all trained/ prepared for the exclusively online teaching/learning. Another important issue induced by our approach is how to solve the schedule of the lectures given the students number constraint, which is a non-trivial optimization problem.

In the near future we plan to develop this strategy to a broader set of students. We plan to cooperate with fellow researcher from different fields, such as psychology, educational sciences and sociology in order to extend our knowledge about this phenomenon.

We also plan to improve this method for the next academic year and implement it to students from other faculties. 


\section{REFERENCES}

Corneli, J. and Danoff, C. J., 2011. Paragogy, In: Proceedings of the 6th Open Knowledge Conference, Berlin, Germany. Corneli, J. and Danoff, C. J., 2011. Paragogy: Synergizing individual and organizational learning, published on Wikiversity. Cornwall, A., and Jewkes, R., 1995. What is participatory research? Social Science and Medicine, 14, 1667-1676.

Dede, C., 2005. Planning for neomillennial learning styles EDUCAUSE Quarterly, 28(1), 7-12.

Ellis, R. A., et al, 2009. E-learning in higher education: Some key aspects and their relationship to approaches to study. Higher Education Research \& Development, 28(3), 303

Fern, E. F., 1982. The use of focus groups for idea generation: The effects of group size, acquaintanceship and moderation on response quantity and quality. Journal of Marketing Research, 19, 1-13.

Flores, J. G., and Alonso, C. G., 1995. Using focus groups in educational research: Exploring teachers' perspectives on educational change. Evaluation Review, 19, 84-101.

Freitas, H., et al, 1998. The focus group, a qualitative research method: reviewing the theory, and providing guidelines to its planning. 1-22.

Green, J. M., et al, 2003. Shortcuts to safety: Risk and 'rules of thumb' in accounts of food choice. Health, Risk and Society, $5,33-52$.

Hattie, J., 2011. Visible Learning for Teachers: Maximizing Impact on Learning, Trade Paperback

Hayward, C., et al, 2004. Still left out in the cold: Problematising participatory research and development. Sociologia Ruralis, 44, 95-108.

Herlo, D., 2016. IT tools in initial teacher training, in Proceedings of the International Conference e-Learning 2016, Madeira, Portugal, July 1-4, 2016, Edited by Miguel Baptista Nunes, Maggie McPherson, ISBN: 978-989-8533-51-7, pp. 85-92

Herlo, D., 2016. Paragogy. New concept of learning in the information society, pp. 159-174, in Volume: Crașovan, M., (coord), Educație-evaluare-integrare, Editura Universității de Vest din Timișoara, ISBN978-973-125-489-0

Hodges, C., Moore, St., Lockee, B., Trust, T., Bond, A., 2020. The Difference Between Emergency Remote Teaching and Online Learning - Retrived from https://er.educause.edu/articles/2020/3/the-difference-between-emergency-remoteteaching-and-online-learning

Howe, N., and Strauss, W., 2000. Millennials rising: The next great generation New York: Vintage.

Kamberelis, G., and Dimitriadis, G., 2005. Focus groups: Strategic articulations of pedagogy, politics, and inquiry. In N. K. Denzin, and Y. S. Lincoln (Eds.), The Sage Handbook of Qualitative Research, 3rd ed. (pp. 887-907). Thousand Oaks, CA: Sage Publications Inc.

Krueger, R. A., and Casey, M. A., 2000. Focus groups: A practical guide for applied research, 4th ed. Thousand Oaks, CA: Sage Publications Inc.

Mendes de Almeida, P. F., 1980. A review of group discussion methodology. European Research, 8, 114-120.

Mezirow, J., 1991. Transformative Dimensions of Adult Learning. San Francisco, CA: Jossey-Bass

Morgan, D. L., 1996. Focus Groups. Annual Review of Sociology, 22, 129-152.

Oblinger, D. G., and Oblinger, J. L., 2005. Educating the net generation Boulder, CO: EDUCAUSE.

Prensky, M., 2001. Digital natives, digital immigrant On the Horizon, 9(5), 15-24.

Sangrà, A., et al, 2012. Building an Inclusive Definition of E-Learning: An Approach to the Conceptual Framework, Retrived from http://www.irrodl.org/index.php/irrodl/article/view/1161/2146

Tapscott, D., 2008. Grown up digital: How the net generation is changing your world New York: McGraw-Hill.

Taylor, S., 2019. The psychology of pandemics: Preparing for the next global outbreak of infectious disease. Cambridge Scholars Publishing.

Thomas, L., et al, 1995. Comparison of focus group and individual interview methodology in examining patient satisfaction with nursing care. Social Sciences in Health, 1, 206-219.

Yousuf, M.I., 2007. The Delphi technique. Essays in Education, 20, 80-89. 